\begin{abstract}
We developed an alternative capture-and-release method for sharks using a simple poker-andhook tool for divers to quickly capture nurse sharks (Ginglymostoma cirratum) entering the intake canal of a nuclear power plant in Florida. The capture technique consists of using a short metal rod (poker) with a barbless J-hook (size 10/0) to snag the base of a shark's tail (caudal peduncle), then safely hauling the individual into a boat by the buoy line that has been hooked to its tail. We captured 20 nurse sharks ranging from 11.8 to $80.3 \mathrm{~kg}$, and 9 individuals were monitored over time. Six sharks were released into the canal and 3 sharks were put in an open tank for 23-24 days for daily observations. All hook wounds resulting

\author{
Serge Aucoin (contact author) \\ Steve Weege \\ Max Toebe \\ Jeff Guertin \\ Jonathan Gorham \\ Michael Bresette \\ Email address for contact author: saucoin@gmail.com \\ Inwater Research Group \\ 4160 NE Hyline Drive \\ Jensen Beach, Florida 34957
} from this technique were assessed between 9 and 42 days, and no ill effects were observed throughout the study period. The capture method caused a small superficial wound to the caudal peduncle that averaged $11.3 \mathrm{~mm}^{2}$ (standard deviation 8.7; $n=23$ ). Wound closure was observed after 9 days and re-epithelialization was almost complete (or the wound had completely healed) between 22 and 42 days. Landing nurse sharks this way is less traumatic than traditional methods (e.g., angling, netting). This study provides preliminary information on, and validates, the use of this tool as an efficient and less invasive capture method than traditional methods and as a method that could be applied to broader areas of shark research.

Manuscript submitted 26 November 2016 Manuscript accepted 28 July 2017.

Fish. Bull. 115: 484-495 (2017).

Online publication date: 15 August 2017. doi: 10.7755/FB.115.4.5

The views and opinions expressed or implied in this article are those of the author (or authors) and do not necessarily reflect the position of the National Marine Fisheries Service, NOAA.
Capturing animals is often a necestivities and ecological research. Studies involving the capture of animals have enabled researchers to understand certain species behavior that otherwise would not have been possible (e.g., intraspecific competition; Hoelzer, 1990; Webster and Hixon, 2000) or to uncover some of the social factors influencing physiological processes (e.g., sex-reversal; Shapiro and Boulon, 1982; Goodwin, 2009). Capture-recapture methods with various types of tags for surveying animals have also allowed researchers to track the movement of species (Kohler et al., 1998; Wiley and Simpfendorfer, 2007), determine species range (Kramer and Chapman, 1999), estimate population size (Pine et al., 2003; Gwinn et al., 2011), and assess other demographic parameters (e.g., Zeller and Russ, 1998; Jones et al., 1999) that have contributed to our understanding of the natural world and facilitated resource management (Davis and Dodrill, 1989; Clark and Kaimmer, 2006).

Trapping, chemical immobilization, and many other methods have sary part of wildlife management ac-

\title{
A new underwater shark capture method used by divers to catch and release nurse sharks (Ginglymostoma cirratum)
}

been used to capture animals for research, relocation, and other management purposes (Williams et al., 2002; Silvy, 2012). Ethically, capture methods should aim to minimize animal suffering (Cuthill, 1991; Jenkins et al., 2014), as well as reduce stress responses, which can bias many types of data collected (Sheriff et al., 2011; Gallagher et al., 2014). Ideally, capture methods should be developed and refined by experienced wildlife biologists and technicians who have studied, planned, and tested methods before starting any wildlife research or management program (Schemnitz et al., 2012).

Knowledge of the behavior and activity patterns of the targeted species is necessary to maximize capture efficiency when developing capture methods. The nurse shark (Ginglymostoma cirratum) was the target species in this study. It is a bottom-dwelling opportunistic predator that feeds primarily on small fish and some invertebrates (Castro, 2000). Juveniles are typically found on the bottom of shallow coral reefs, seagrass flats, and around mangrove islands. Older individuals typically 
reside in and around deeper reefs and rocky areas, where they tend to seek shelter in crevices and under ledges during the day and leave their shelter at night to feed on the seabed in shallower areas (Castro, 2000).

Nurse sharks have a wide but patchy geographical distribution along tropical and subtropical coastal waters of the eastern Atlantic Ocean, western Atlantic Ocean, and eastern Pacific Ocean (Campagno, 2002; Karl et al., 2012). They have long residency times and show strong site fidelity (typical of reef sharks), and they are one of the few shark species known to exhibit mating-site fidelity (Carrier et al., 2004). Nurse sharks are also exceptionally sedentary, unlike most other shark species (Heithaus et al., 2007; Karl et al., 2012; Whitney et al., 2016). They are targeted directly in some fisheries and are considered as bycatch in others. The conservation status of the nurse shark is globally assessed as being data deficient in the IUCN List of Threatened Species owing to the lack of information across its range in the eastern Pacific Ocean and eastern Atlantic Ocean (Rosa et al., 2006). They are considered to be a species of least concern in the United States and in The Bahamas, but considered to be near threatened in the western Atlantic Ocean because of their vulnerable status in South America and reported threats throughout many areas of Central America and the Caribbean (Rosa et al., 2006).

Nurse sharks are known to be robust and able to tolerate capture, handling, and tagging extremely well (Carrier, 1985; Dooley and Flajnik, 2005) and are an important species for shark research (predominantly in physiology). Over $30 \%$ of current studies from all published research on 29 reef shark species have focused on nurse sharks (Osgood and Baum, 2015). Studies that involved capturing nurse sharks have successfully used fishing nets or baited hook-and-line gear, but these methods are not without limitations or problems (Garla et al., 2006; Skomal, 2007; Gallagher et al., 2014). These traditional capture methods can prolong treatment and handling times on account of gear entanglement and recovery delays (Smith, 1992; Mandelman and Farrington, 2007; Morgan and Carlson, 2010) or cause severe hooking injuries that increase morbidity and mortality (Bansemer and Bennett, 2010; Danylchuk et al., 2014).

Shark survival and recovery after capture varies widely and depends on a variety of factors (reviewed in Skomal and Bernal, 2010). Assessing 25 species of chondrichthyans (i.e., evaluating $>11,000$ sharks, rays, and chimaeras) in a commercial shark fishery, Braccini et al. (2012) indicated postcapture survival to be generally high. Tracking studies on the postrelease mortality of lemon sharks (Negaprion brevirostris) and Atlantic sharpnose sharks (Rhizoprionodon terraenovae) captured by baited hook-and-line gear indicated a 10-12.5\% postrelease mortality rate for these species (Gurshin and Szedlmayer, 2004; Danylchuk et al., 2014), but this may be an underestimate owing to either low sample sizes or to short monitoring times, or both (i.e., delayed mortality due to infection and disease).

Hooking injuries are considered the primary cause of angling-related mortality and are the result of many factors, including hook type and hook configuration, as well as fishing technique and experience (see Brownscombe et al., 2017). Moreover, evidence indicates that cartilaginous skeletons of sharks do not heal properly after damage (Ashhurst, 2004), thus hooking trauma to cartilaginous structures in the jaw or skull may have long lasting impacts.

In this study, we present technical information on a more efficient and less invasive capture method that we used to catch and release nurse sharks. The technique involves hooking the area of the caudal peduncle (between the caudal fin and $2^{\text {nd }}$ dorsal fin) where shark skin is thick and posterior musculature has been reported as being the most damage-tolerant area (Towner et al., 2012). The tail base is also away from the more vascularized tissues and sensory organs concentrated anteriorly (e.g., gills, eyes, nostrils, ampullae of Lorenzini, mandibular neuromasts; Hueter et al., 2004). The resulting damage to these areas from typical baited fishing, as well as gut injuries from swallowed hooks, can render sharks more susceptible to late onset morbidity and mortality (Bansemer and Bennet, 2010). Although the remarkable ability of sharks to heal quickly from various types of body wall and other types of injuries has long been documented (Olsen, 1953; Bird, 1978; Reif, 1978; Towner et al., 2012; Kessel et al., 2017), we examined wound recovery from this new poker-and-hook method for up to a 42-day period to validate its use as a minimally invasive capture technique for sharks.

\section{Materials and methods}

\section{Study area}

Nurse sharks will occasionally inhabit the seawater intake canal at the Florida Power and Light St. Lucie Nuclear Power Plant located on Hutchinson Island, Florida (Fig. 1). The offshore intake pipes that draw cooling water (365 $\mathrm{m}$ offshore, $7 \mathrm{~m}$ off the seafloor) use velocity caps that effectively deter and reduce fish from entering (see review by Fedorenko, 1991), but some nurse sharks and other marine wildlife still enter from time to time (Bresette et al., 1998).

Marine wildlife entering the canal need to be removed by biologists in order to return them to their natural habitat. In the past, nurse sharks that entered the canal were captured by traditional baited hook-and-line gear (e.g., rod and reel, hand lines), but the use of these methods in the canal can take hours to land a few individuals, if any. The inefficiency of these methods in this case is due to the tendency of nurse sharks to aggregate at discharge ends of the canal intake pipes where strong currents and obstructions (e.g., pier columns) occur and can pre- 


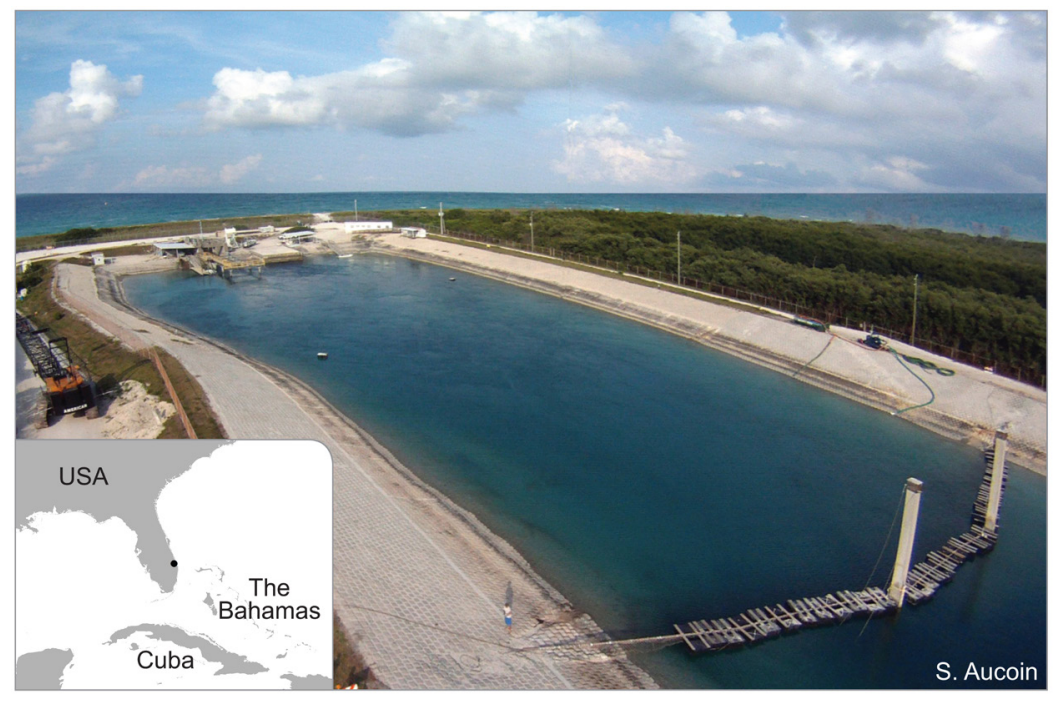

Figure 1

Photograph and location of the intake canal of the Florida Power and Light St. Lucie Nuclear Power Plant on Hutchinson Island, where nurse sharks (Ginglymostoma cirratum) were captured with the poker-and-hook tool and monitored to evaluate this new underwater method for catching sharks.

gen, 2012). Once the tail base was hooked, the cable ties broke or slid off as a result of the shark swimming away with the hook (with the poker remaining in hand) and the line, now attached to the shark, was released. A short video demonstrating this underwater capture technique is available (video).

We then used a 4-m boat with low sides (i.e., modified gunnels) and pulled in the line by hand until the shark's tail could be used to haul the individual onboard. For large sharks ( $\geq 70 \mathrm{~kg})$, we lassoed the shark's tail at the water surface to facilitate hauling these heavier individuals into the boat. None of the nurse sharks we hauled into the boat exhibited any stressinduced vertebral 'popping' (dislocation of vertebrae) that can occur when lifting large fish by their tail (e.g., Pacific halibut [Hippoglossus stenolepis], senior author, personal observ.). Once onboard, the shark was restrained by hand and our total handling and processing time

vent the deployment of gill nets and can easily sever fishing lines.

\section{Equipment and capture technique}

The poker-and-hook tool consisted of a long shanked stainless-steel J-hook (size 10/0 with its barb removed) attached to an 80-cm twine leader (90-kg test), a 20-m rope and retrieval buoy, and a $90-\mathrm{cm}$ metal rod (the poker) (Fig. 2A). We wrapped the twine leader 2-3 times around the poker to avoid entanglement underwater (Fig. 2B). The steel hook was fastened to the poker with 2 -mm cable ties: 2 cable ties were threaded through a hole at the end of the poker and through the eye of the hook, and a third cable tie cinched the hook towards the tip (Fig. 2C). We also flattened the back of the hook and the tip of the poker for added stability, and lightly scored the cable ties to facilitate their breaking under pressure.

To capture a nurse shark, a diver descended to the targeted individual with the poker-and-hook tool in hand, keeping the twine leader taut (Fig. 2B) and hooked the side of the caudal peduncle (region between the anal and tail fins); hereafter, referred to as the tail base (Fig. 3). The diver aimed to hook the upper- or lower-lateral part of the nurse shark's tail base because the species is primarily a nocturnal feeder and therefore frequently dependent on its lateral line for feeding. Moreover, the skin of the upper and lower parts of the tail base in sharks is often thicker and adjoining muscle below the skin is also less vascularized than that of the middle-lateral part (Shadwick and Goldbo- was under $5 \mathrm{~min}$. This period included the time to dock the boat and to move the individual with a wet push cart to a weigh station, to a holding tank, or to the beach for release (see next section).

\section{Postcapture monitoring and wound assessment}

A total of 20 nurse sharks were captured and released between 8 August and 23 October 2014. At first, 4 sharks were removed from the canal by using this new technique. These nurse sharks ranged from 48.9 to $79.6 \mathrm{~kg}$ and experienced hook wounds that were relatively superficial (i.e., shallow punctures with no bleeding). After each individual was examined, we recorded weight, maximum total length, and took photos of hook wounds to scale. All the sharks were released back into the ocean without issue.

We then proceeded to capture 16 more sharks ranging from 11.8 to $80.3 \mathrm{~kg}$, but this time we assessed hook wounds in a more systematic way. When sharks were hauled into the boat, we first measured hook penetration if the hook did not fall out, which was often the case. Hook penetration or depth was reported as the straight distance between the tip of the hook to the first visible part of the hook shank at the surface of the shark's skin. Of these 16 sharks captured, we released 6 nurse sharks ranging from 11.8 to $43.8 \mathrm{~kg}$ back into the canal and 3 sharks ranging from 14.9 to $21.2 \mathrm{~kg}$ were put into a nearby $3-\mathrm{m}$ diameter open flow-through tank $(\sim 0.5$ $\mathrm{L} / \mathrm{s}$ ) in the shade. All sharks $>48.9 \mathrm{~kg}$ were returned to the ocean to reduce handling large individuals a second time, and these returned sharks included 2 individu- 

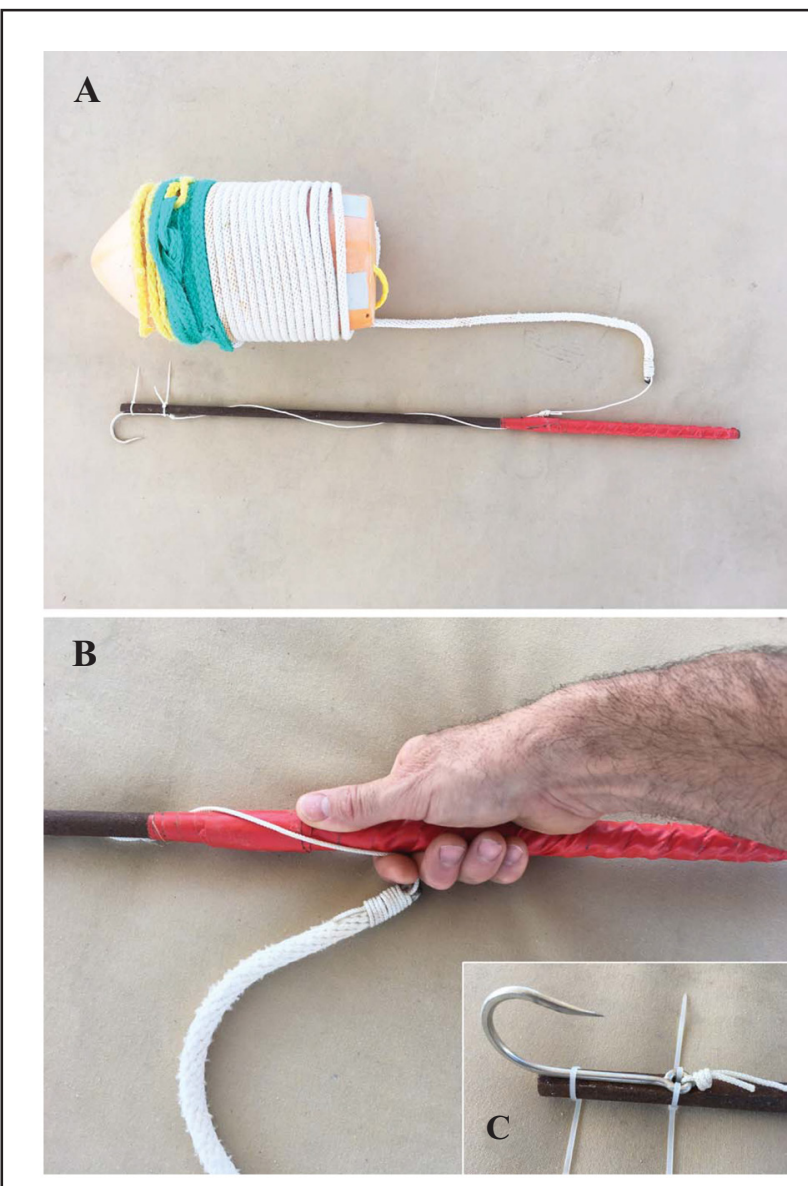

Figure 2

Images of (A) the poker-and-hook gear used to capture nurse sharks (Ginglymostoma cirratum) in this study, (B) how the lead line or ganion is kept taut around the poker (line and rope awareness is critical to avoid diver entanglement), and (C) how the cable ties are threaded through the eye of the hook and the hole at the end of the poker and used to cinch the hook bend at the poker tip. als that we suspected were pregnant $(64.8 \mathrm{~kg}, 66.0 \mathrm{~kg}$; see Castro, 2000). Two more sharks were released into the ocean $(14.2 \mathrm{~kg}, 32.0 \mathrm{~kg})$ because we already had a number of similar-size individuals. We monitored the 6 sharks in the canal by snorkeling when water clarity permitted, whereas the 3 sharks in the tank were observed daily (and with video footage) and fed every 3-4 days. The 3 sharks released in the holding tank were then re-assessed after 23-24 days and the sharks in the canal were randomly recaptured and re-assessed between 9 and 42 days. All individuals were tagged with numbered plastic Rototags ${ }^{1}$ (Dalton ID Systems Ltd., Henley-on-Thames, UK) on their dorsal fins (see Latour, 2005), their weight and total length were recorded, and their hook wounds were photographed to scale.

To standardize our evaluation of each hook wound, we first put a measuring tape next to the wound and photographed both the wound and tape together with the camera lens directly above the plane of the skin surface. We then quantified hook wounds by processing digital images in Adobe Photoshop CC, vers. 2015 (Adobe Systems, Inc., San Jose, CA) to calculate the geometrical parameters of wound severity: wound area; circumference; and circularity by using the Photoshop ruler tool to measure pixel length to scale, and then manually outlining the wound margin with the polygonal lasso tool (Sedgewick, 2008). Recording the 4 parameters of hook depth, wound area, circumference, and circularity provided baseline data on initial wound status. Because medical studies show that wound area and circumference correlate with wound volume (Melhuish et al., 1994; Flanagan, 2003), we used SPSS Statistics, vers. 20.0.0 (IBM Corp., Armonk, NY) to examine wound area in relation to hook depth (as a proxy for wound volume) by applying an analysis of covariance (ANCOVA), with shark body size as the covariate. To further examine hook injury, specifically,

\footnotetext{
${ }^{1}$ Mention of trade names or commercial companies is for identification purposes only and does not imply endorsement by the National Marine Fisheries Service, NOAA.
}

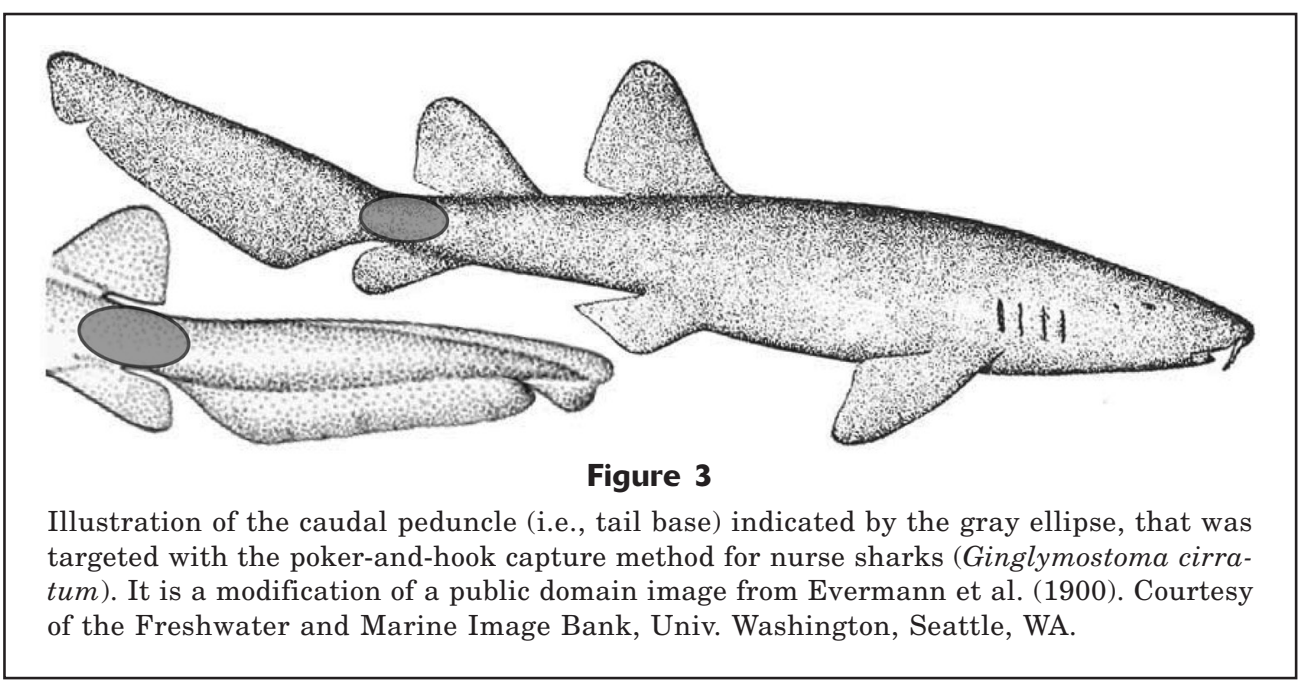




\section{Table 1}

Description of nurse sharks (Ginglymostoma cirratum) captured with the poker-and-hook method in a nuclear power plant intake canal in Florida during 2014, and resulting hook wound characteristics. Minimum bleeding indicates either a few drops of blood (Fig. 4A) or residual blood (Fig. 4E) observed once individuals were hauled into the boat. Circularity is defined as $4 \pi$ (area/circumference $\left.{ }^{2}\right)$, where a value of 1 indicates a perfect circle and a value approaching 0 indicates an increasingly elongated shape (i.e., skin tear). Hook depth is a relative measure that was recorded as the straight distance between the tip of the hook to the first visible part of the hook shank at the surface of the shark's skin. A superscript $R$ signifies recapture and identifies individuals captured twice by the poker-and-hook method. Principal component analysis (PCA) with weight and length together was used to indicate a score for shark body size. $f / o=f e l l$ out (hook fell out by itself when the shark was landed). $\mathrm{n} / \mathrm{a}=$ not available (hook depth not measured). A mean and standard deviation (SD) are given for wound area, circumference, and circularity.

\begin{tabular}{|c|c|c|c|c|c|c|c|c|}
\hline $\begin{array}{l}\text { Weight } \\
(\mathrm{kg})\end{array}$ & $\begin{array}{c}\text { Total } \\
\text { length } \\
(\mathrm{cm})\end{array}$ & $\begin{array}{l}\text { PCA } \\
\text { score }\end{array}$ & Sex & $\begin{array}{l}\text { Hook } \\
\text { depth } \\
(\mathrm{mm})\end{array}$ & $\begin{array}{c}\text { Hematuria } \\
\text { (bleeding) }\end{array}$ & $\begin{array}{l}\text { Area } \\
\left(\mathrm{mm}^{2}\right)\end{array}$ & $\begin{array}{l}\text { Circumference } \\
\quad(\mathrm{mm})\end{array}$ & $\begin{array}{c}\text { Circularity } \\
\quad(0-1)\end{array}$ \\
\hline \multirow[t]{2}{*}{$11.8^{\mathrm{R}}$} & 135 & -1.445 & M & $f / o$ & minimal & 2.2 & 11.2 & 0.21 \\
\hline & & & & 37 & none & 10.0 & 21.3 & 0.50 \\
\hline 12.7 & 137 & -1.397 & $\mathrm{~F}$ & 24 & minimal & 21.9 & 38.2 & 0.39 \\
\hline 14.2 & 143 & -1.282 & $\mathrm{M}$ & 29 & none & 8.5 & 15.1 & 0.47 \\
\hline 14.2 & 145 & -1.255 & $\mathrm{~F}$ & $f / o$ & none & 3.6 & 26.6 & 0.06 \\
\hline 14.9 & 151 & -1.158 & $\mathrm{~F}$ & 23 & none & 10.5 & 30.1 & 0.15 \\
\hline 19.8 & 163 & -0.886 & $\mathrm{M}$ & 19 & minimal & 10.1 & 14.1 & 0.64 \\
\hline 21.2 & 167 & -0.800 & M & 16 & minimal & 6.9 & 26.6 & 0.12 \\
\hline 32.0 & 186 & -0.302 & $\mathrm{~F}$ & 33 & minimal & 18.9 & 28.4 & 0.30 \\
\hline \multirow[t]{2}{*}{$41.2^{\mathrm{R}}$} & 204 & 0.148 & M & 35 & none & 10.1 & 12.3 & 0.85 \\
\hline & & & & $\mathrm{f} / \mathrm{o}$ & minimal & 4.8 & 9.0 & 0.75 \\
\hline 43.7 & 205 & 0.217 & M & 23 & minimal & 13.0 & 49.8 & 0.07 \\
\hline 43.8 & 209 & 0.274 & M & 21 & none & 7.8 & 15.0 & 0.43 \\
\hline 48.9 & 210 & 0.401 & $\mathrm{~F}$ & $\mathrm{f} / \mathrm{o}$ & none & 13.9 & 19.4 & 0.43 \\
\hline 52.9 & 211 & 0.504 & M & 18 & minimal & 5.2 & 17.3 & 0.22 \\
\hline 52.9 & 218 & 0.599 & $\mathrm{~F}$ & 24 & minimal & 2.3 & 7.0 & 0.58 \\
\hline 56.5 & 238 & 0.951 & M & $\mathrm{f} / \mathrm{o}$ & minimal & 5.2 & 9.8 & 0.68 \\
\hline 60.0 & 214 & 0.703 & $\mathrm{~F}$ & $\mathrm{n} / \mathrm{a}$ & minimal & 37.8 & 30.6 & 0.51 \\
\hline 64.8 & 233 & 1.068 & $\mathrm{~F}$ & $\mathrm{n} / \mathrm{a}$ & none & 10.0 & 15.1 & 0.54 \\
\hline \multirow[t]{2}{*}{$66.0^{\mathrm{R}}$} & 231 & 1.067 & $\mathrm{~F}$ & 25 & minimal & 16.7 & 27.0 & 0.29 \\
\hline & & & & 37 & minimal & 6.8 & 11.5 & 0.65 \\
\hline 79.6 & 222 & 1.248 & $\mathrm{~F}$ & 15 & none & 5.6 & 17.6 & 0.44 \\
\hline \multirow[t]{3}{*}{80.3} & 245 & 1.576 & $\mathrm{~F}$ & 38 & minimal & 29.4 & 24.9 & 0.60 \\
\hline & & & & & Mean & 11.3 & 20.8 & 0.43 \\
\hline & & & & & SD & $(8.7)$ & $(10.4)$ & $(0.22)$ \\
\hline
\end{tabular}

circularity (defined as $4 \pi\left(\right.$ area/circumference $\left.^{2}\right)$ ) as an index of skin tearing in relation to shark size, we used a binomial logistic regression, which included calculating the Nagelkerke pseudo-coefficient of determination (Nagelkerke pseudo- $r^{2}$ ) and the Homer-Lemeshow test of the goodness of fit to help explain the overall model. In this case, we used categories more severe (circularity $\leq 0.5$ ) and less severe (circularity $>0.5$ ), where a value approaching 0 indicates an increasingly elongated shape and therefore a more pronounced skin tear. The Omnibus test of model coefficients (i.e., likelihood ratio chi-square test) was used for the overall model, whereas the Wald chi-square test was used for the odds ratio (see McCormick and Salcedo, 2017).

Before-and-after photos of hook wounds were used to re-assess 3 nurse sharks recaptured after 9-10 days, 4 nurse sharks after 22-24 days, and 2 nurse sharks after 37-42 days. We included all hook wounds $(n=23)$ to calculate descriptive statistics, which included 2 individuals captured twice because they escaped from our boat the first time, and 1 individual recaptured over time. Anglers targeting large groupers recaptured the remaining 5 nurse sharks in the canal. We compared before-and-after weights of 4 nurse sharks after 22-24 days ( 1 nurse shark in the canal and 3 sharks in the tank). To minimize handling time, the 5 other sharks released in the canal were weighed only before being released in the ocean.

\section{Results}

Table 1 shows shark description and wound information, including mean values for wound area, circularity, 


\section{Table 2}

The logistical binary regression applied to data from nurse sharks (Ginglymostoma cirratum) captured with the poker-and-hook method in Florida during 2014 to ascertain the effects of body size on the likelihood of more pronounced skin tears (i.e., circularity $\leq 0.5)$ produced a significant model $\left(\chi^{2}(1)=6.124, P=0.01\right)$. The model explained $31.7 \%$ (Nagelkerke pseudocoefficient of determination [pseudo- $r^{2}$ ]) of the variance in the outcome and correctly classified $73.9 \%$ of cases. The output for variables in the equation indicated that increasing body size was associated with a $72 \%$ reduction in the likelihood of exhibiting more pronounced skin tears (odds ratio: 0.279 ) when the 10/0 barbless J-hook was used in our study. The asterisk (*) indicates statistical significance $(\alpha<0.05)$; $\beta=$ beta weight coefficient (i.e., intercept); $\mathrm{SE}=$ standard error; Wald=Wald chi-square value; $d f=$ degrees of freedom; $\operatorname{Exp}(\beta)=$ exponentiation of the coefficients (i.e., odds ratios for the predictors).

\begin{tabular}{lllllll}
\hline & & & & \multicolumn{3}{c}{$P$} \\
& \multicolumn{1}{c}{$\mathrm{SE}$} & Wald & $\mathrm{df}$ & value & $\operatorname{Exp}(\beta)$ \\
\hline Body size & -1.277 & 0.608 & 4.411 & 1 & $0.036^{*}$ & 0.279 \\
Constant & 14.9 & 0.524 & 1.449 & 1 & 0.229 & 1.878 \\
& & & & & & \\
\hline
\end{tabular}

and circumference. Hook depth (as a proxy for wound volume) in relation to wound area, circularity, and circumference was initially examined. Because the variables are correlated (different types of measurements of the same wound) we first tested for multicollinearity, which indicated dropping the variable circumference in subsequent analysis. We then tested whether wound area predicted hook depth by using ANCOVA. Because measurements of shark weight and total length were strongly positively correlated, we used a principle component analysis to reduce these variables into component scores as a better indicator of shark body size (i.e., as a covariate) and to increase the degrees of freedom available to estimate variability. Nonetheless, the model did not reveal any significant relationship between wound area and hook depth or body size.

The logistical binary regression applied to ascertain the effects of body size on the likelihood of more pronounced skin tears (i.e., circularity $\leq 0.5$ ) produced a significant model, indicated by the Omnibus test of model coefficients $\left(\chi^{2}(1)=6.124, P=0.01\right)$, with the Hosmer-Lemeshow test strongly suggesting the model was a good fit to the data $(P=0.42)$. The model explained $31.7 \%$ (Nagelkerke pseudo- $r^{2}$ ) of the variance in the outcome, correctly classified $73.9 \%$ of cases, and the odds ratio indicated that increasing body size was associated with a $72 \%$ reduction in the likelihood of exhibiting more pronounced skin tears when using the 10/0 barbless J-hook in our study (Table 2).

Photos were taken to measure wound and healing progression over time; all wounds were nearly or completely healed after 22 days. Typical healing stages for

\section{Table 3}

Difference in weight at capture and 22-24 days after recapture for 4 nurse sharks (Ginglymostoma cirratum) captured by the poker-and-hook method and released in Florida during 2014. The remaining sharks sampled for this study were weighed only upon their release back into the ocean to minimize handling time.

\begin{tabular}{lccccc}
\hline $\begin{array}{l}\text { Total } \\
\text { length } \\
(\mathrm{cm})\end{array}$ & $\begin{array}{c}\text { Initial } \\
\text { weight } \\
(\mathrm{kg})\end{array}$ & $\begin{array}{c}\text { Final } \\
\text { weight } \\
(\mathrm{kg})\end{array}$ & $\begin{array}{c}\text { Weight } \\
\text { gain } \\
(\mathrm{kg})\end{array}$ & $\begin{array}{c}\text { Time } \\
(\mathrm{d})\end{array}$ & $\begin{array}{c}\text { Gain } \\
\text { rate } \\
(\mathrm{g} / \mathrm{d})\end{array}$ \\
\hline 135 & 11.8 & 12.1 & 0.3 & 22 & 14 \\
151 & 14.9 & 15.5 & 0.6 & 23 & 27 \\
163 & 19.8 & 20.3 & 0.5 & 24 & 20 \\
167 & 21.2 & 22.0 & 0.8 & 23 & 35 \\
& & & & & \\
\hline
\end{tabular}

small wounds in nurse sharks begin with mucus secretion, followed by wound contraction, epidermal expansion, and scale neogenesis (Reif, 1978). Figure 4 shows typical before-and-after photos of hook wounds from sampled nurse sharks. At 9-10 days, wounds showed that the dermis had begun regenerating (seen beneath its mucus covering; Fig. 4, A and B) or were already transitioning to the epidermal expansion stage. At 22-24 days, repair scales within a fully regenerated epidermis were obvious (Fig. 4, C and D) and easily identified by their white color (in comparison with fully mineralized scales that are brown). At 37-42 days, only a small scar remained, and although no histological assessment was performed the formed scales appeared to be normal (Fig. 4, E and F), identified by their brown color which was due to pigment deposited together with inner layers of dentine in the skin (Reif, 1978).

Table 3 shows before-and-after weights of 4 nurse sharks re-assessed after 22-24 days. All individuals had gained weight upon recapture (mean: $0.6 \mathrm{~kg}$ [standard deviation 0.2$]$ ). The smallest of these 4 sharks, which was released into the canal, gained less weight than the 3 larger individuals released into the holding tank that were fed regularly.

\section{Discussion}

Studies on the survival of fish after their capture and release are technically challenging and the long-term effects of physical and physiological trauma associated with varying capture techniques remain mostly unknown (Davis, 2002; Skomal and Bernal, 2010; Gallagher, 2015). Recent studies are beginning to document postcapture sharks for extended periods and indicate that capture-related morbidity and mortality in sharks varies widely among species (Brill et al., 2008; Frick et al., 2010; Heberer et al., 2010; Gallager et al., 2014). Although postcapture mortality rates for sharks are still generally considered to be low (Gurshin and 


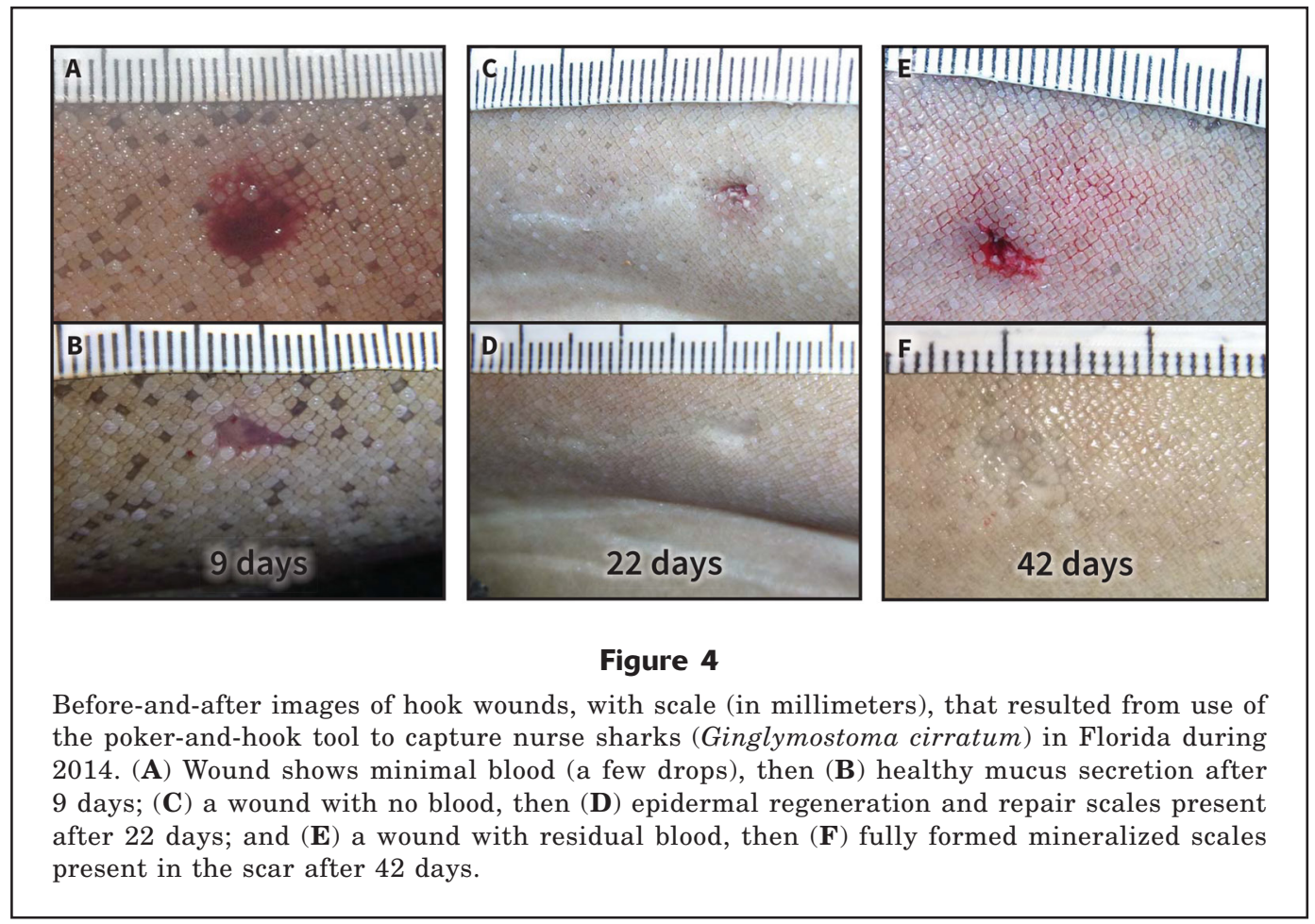

Szedlmayer, 2004; Braccini et al., 2012; Danylchuk et al., 2014), low levels are still arguably of concern for important apex predators such as sharks. Local populations of sharks are likely highly susceptible to even low levels of postcapture mortality because of life history characteristics such as low reproductive output (e.g., litter size) and late age-at-maturity (Stevens et al., 2000; Dulvy and Forrest, 2012).

The intake canal at the Florida Power and Light St. Lucie Nuclear Power Plant provided an ideal environment to monitor nurse sharks over time after their capture by the poker-and-hook method. All 20 nurse sharks captured by this method showed no immediate ill effects and the 9 individuals monitored between 9 and 42 days survived with no observed abnormal behavior (although behavior was not evaluated in a systematic way). All wounds from the poker-and-hook capture method were either healing well or fully healed during this period and no signs of inflammation of tissue deterioration occurred.

The 4 nurse sharks whose weights were recorded before and after 22-24 days all increased in weight. This further corroborates evidence of a quick recovery and minimal postcapture stress. When the 3 nurse sharks were put into the tank, they fed immediately, as well as voraciously, and continued to do so at each feeding every 3-4 days. The sharks were fed to satiation and any uneaten food (freshly chopped fish) or small live fish that we stunned and that settled on the tank bottom would be eaten overnight, thereby suggesting that no injury occurred to the lateral line system (which is used in prey detection and contributes to the localiza- tion of food by the olfactory organs; see Kleerekoper and Gruber, 1975; Gardiner and Atema, 2007; Gardiner, 2012) or that any resulting injury to the lateral line could be deemed negligible.

An important stage in wound healing in sharks is the continual replacement of their dermal denticles (scales) (Reif, 1978). The extraordinarily tough skin of nurse sharks further makes them well suited for the poker-and-hook capture method. Both male and female nurse sharks are characterized by their thick, dense integument known to withstand multiple bites during mating (Klimley, 1980; Pratt and Carrier, 2001) and to resist damage while living in typical habitats of rock and coral (i.e., sustaining collisions with reef substrate during pursuit of prey; Campagno, 2002; senior author, personal observ.). The sides of the tail base are also without lateral keels or precaudal pits that could affect hooking efficacy or injury (or both). More importantly, the main circulatory vessels taper at the tail base (Rosenzweig, 1988), which is dense in muscle and is reported as damage tolerant (Naresh et al., 1997; Towner et al., 2012). The caudal area further appears to be well suited for this capture method because evidence suggests that drawing blood from this area is also less physiologically taxing (Cooper and Morris, 1998; Mandelman and Skomal, 2009) and the upperand-lower targeted part of the tail base (away from the lateral line) has very little vascularization (Shadwick and Goldbogen, 2012).

Of the 23 hook wounds resulting by this capture method, 9 hook wounds did not bleed and 14 hook wounds showed only minimal bleeding (a couple drops 
of blood at most) that quickly coagulated. Although the elasticity in shark skin is connected to internal propulsion muscles (Wainwright et al., 1978; Naresh et al., 1997), swimming and other movements never appeared compromised during regular observations of sharks in the holding tank, nor during our intermittent observations of individuals in the canal.

Values of hook wound parameters that were examined, such as wound area, were small and remained small regardless of shark size (up to $80 \mathrm{~kg}$ ). Medical studies have shown wound area and circumference to correlate with wound volume (Melhuish et al., 1994; Flanagan, 2003), which was not the case with regard to recorded hook depth in our study. Although we recognize our measurements of hook depth were a crude estimate and not necessarily indicative of potential wound sinus formation, the fact that hook penetration was mostly superficial, with the hook often falling out by itself when the shark was hauled onboard, suggests internal injury was minimal. When the hook did penetrate deeper, hook penetration remained parallel to the skin on account of the bend in the J-hook, thus limiting perpendicular penetration. Reducing the hook gap (the space between the hook point and the hook shank) should further reduce perpendicular penetration, but could be more prone to tearing the skin (measured by circularity). Our results indicated that the type and size of hook we used was less prone to tearing the skin of larger individuals than the skin of smaller ones; therefore, it would be useful to experiment with a range of smaller hooks for smaller individuals in future studies.

The poker-and-hook capture method is also well suited for nurse sharks because of their feeding behavior. Nurse sharks are obligate suction feeders capable of generating suction forces that are among the highest recorded for any aquatic vertebrate to date (Tanaka, 1973; Motta et al., 2008). The poker-and-hook capture method prevents many sublethal effects or the delayed mortality that can be caused by traditional baited hook-and-line gear (or prevents both). This is especially the case for more internally hooked fish as has been reported for blue sharks (Prionace glauca; Borucinska et al., 2001; Borucinska et al., 2002) and lemon sharks (Danylchuk et al., 2014). Nurse sharks further exhibit a suck-and-spit behavior or shake their head violently (or exhibit a combination of both) to reduce the size of food items (Motta et al., 2002; Motta, 2004), which could further increase the risk of hooking to sensory and vital organs concentrated anteriorly.

The behavioral response of nurse sharks is also appropriate for the poker-and-hook capture method because nurse sharks in our study always retreated upon being hooked underwater. Nonetheless, as inoffensive as nurse sharks may appear, they are still ranked fourth in documented shark bites on humans (Ricci et al., 2016). Nurse sharks are known to attack when approached too closely, especially in a confined space or if their retreat is prevented (Limbaugh, 1963; Nelson et al., 1986). Our divers using this method were highly experienced in handling underwater wildlife. It is possible that the poker-and-hook method could trigger more erratic or aggressive responses in other shark species, and therefore shark safety and cautious planning are advised with this technique for other species.

Nurse sharks also exhibit relatively subdued fighting during capture compared with that of other sharks (Gallagher, 2015). Fighting intensity and hooking severity could be more pronounced with larger, more aggressive species. The tiger shark (Galeocerdo cuvier) has been captured on the water surface by a similar technique in order to attach satellite transmitters to their dorsal fin (Fitzpatrick et al., 2012). In the latter tiger shark study, a detachable clamp and buoy system was closed around the base of the shark's tail as it swam at the water surface near their boat. Remarkably, video footage of this technique indicates tiger sharks also become quickly subdued after momentarily dragging the attached buoy through the water. Whereas nurse sharks and tiger sharks are known to display more subdued behavior when hooked anteriorly or captured by their tails, blacktip sharks (Carcharhinus limbatus) have shown bouts of intense fighting at the onset of being hooked anteriorly (Gallagher et al., 2017). We speculate that blacktip sharks, as well as other shark species that exhibit intense fighting behavior when hooked anteriorly, would also fight intensely if captured by the tail.

Shark breathing is another important consideration when using the poker-and-hook method to capture different shark species. Although most sharks are facultative ram ventilators some are obligate ram ventilators that need to swim continuously to breathe (Milsom and Taylor, 2015). The common thresher shark (Alopias vulpinus) is an example of an obligate ram ventilator, and therefore pulling this species backwards or adding drag would affect their breathing and survival (Heberer et al., 2010; Sepulveda et al., 2015). Interestingly, common thresher sharks are usually pulled in backwards when fished because their caudal fin gets hooked when trying to immobilize bait perceived as prey (Aalbers et al., 2010). Large common thresher sharks do not survive capture times >85 min, unlike smaller common thresher sharks or individuals landed with much shorter capture times (Cartamil et al., 2010; Heberer et al., 2010).

Capture time has been identified as a critical factor in postrelease survival (Cooke and Suski, 2005). Nurse sharks in the canal were landed within a few minutes with the poker-and-hook capture method and with less effort than when similar-size individuals were landed by baited hook-and-line gear. It is likely that sharks were simply less agitated and traumatized when hooked posteriorly than when hooked anteriorly. However, pulling the shark backwards (with the buoy line attached to the shark tail) may have affected the functional mobility of the caudal fin or general swimming behavior, thus impairing thrust or swimming speed (see Wilga and Lauder, 2002). It is also possible that the backward motion or inverted position of the 
shark being hauled in may have induced an immobility reflex or slight tonic immobility state as documented for a number of shark species (Henningsen, 1994; Holland et al., 1999).

Little scientific attention has been given to the process of wound healing in sharks (Towner et al., 2012) and little is known about related shark behavior. Our study area provides favorable conditions for pursuing this line of research on nurse sharks and our continued use of the poker-and-hook method could provide valuable insight on the process of wound healing in sharks in general. In the future, the effects on blood biochemistry (as an indicator of stress response, morbidity, etc.) could also be examined in relation to postcapture behavior and survivorship in comparison with other capture methods (e.g., Hyatt et al., 2012; Hyatt et al., 2016). Currently, strong evidence supports the continued use and development of the poker-and-hook method and its application in research. Compared with traditional methods such as angling or gillnetting, the poker-and-hook method is less invasive and more efficient. Targeted individuals are captured quickly and efficiently, thereby reducing capture time and associated stress, and bycatch can be entirely eliminated with this method.

As of March 2016, 5 individuals captured with the poker-and-hook method, tagged and then released, have returned to the canal and have provided information on residency and movement of nurse sharks in the area. Given the increasing importance of tagging for understanding the connectivity between individual mobility (e.g., range, residency), the internal dynamics of populations (e.g., mating aggregations, philopatry), and the effective management of nurse shark populations at large (Chapman et al., 2015), we recommend using the poker-and-hook capture method to facilitate tagging and subsequent tracking of nurse sharks elsewhere, as well as other feasible shark species.

\section{Acknowledgments}

We would like to thank Florida Power and Light and the St. Lucie Nuclear Power Plant for their support. We would also like to thank N. Álvarez-Berríos, C. Bajzak, and 3 anonymous reviewers who provided constructive input to this manuscript. All fish removal activities in the canal were in accordance with the latest special activities license issued by the Florida Fish and Wildlife Conservation Commission (permit no. SAL-15-0018-SR).

\section{Literature cited}

Aalbers, S. A., D. Bernal, and C. A. Sepulveda.

2010. The functional role of the caudal fin in the feeding ecology of the common thresher shark Alopias vulpinus. J. Fish Biol. 76:1863-1868. Article
Ashhurst, D. E.

2004. The cartilaginous skeleton of an elasmobranch fish does not heal. Matrix Biol. 23:15-22. Article

Bansemer, C. S., and M. B. Bennett.

2010. Retained fishing gear and associated injuries in the east Australian grey nurse sharks (Charcharias taurus): implications for population recovery. Mar. Freshw. Res. 61:97-103. Article

Bird, P. M.

1978. Tissue regeneration in three carcharhinid sharks encircled by embedded straps. Copeia 1978:345-349.

Borucinska, J., J. Martin, and G. Skomal.

2001. Peritonitis and pericarditis associated with gastric perforation by a retained fishing hook in a blue shark. J. Aquat. Anim. Health 13:347-354. Article

Borucinska, J., N. Kohler, L. Natanson, and G. Skomal.

2002. Pathology associated with retained fishing hooks in blue sharks, Prionace glauca (L.), with implications for their conservation. J. Fish. Dis. 25:515-521. Article

Braccini, M., J. van Rijn, and L. Frick.

2012. High post-capture survival for sharks, rays and chimaeras discarded in the main shark fishery of Australia? PLoS ONE. 7:e32547. Article

Bresette M., J. Gorham, and B. Peery.

1998. Site fidelity and size frequencies of juvenile green turtles (Chelonia mydas) utilizing near shore reefs in St. Lucie County, Florida. Mar. Turtle Newsl. 82:5-7.

Brill, R., P. Bushnell, S. Schroff, R. Seifert, and M. Galvin.

2008. Effects of anaerobic exercise accompanying catchand-release fishing on blood-oxygen affinity of the sandbar shark (Carcharhinus plumbeus, Nardo). J. Exp. Mar. Biol. Ecol. 354:132-143. Article

Brownscombe, J. W., A. J. Danylchuk, J. M. Chapman, L. F. G. Gutowsky, and S. J. Cooke.

2017. Best practices for catch-and-release recreational fisheries-angling tools and tactics. Fish. Res. 186:693-705. Article

Campagno, L. J. V.

2002. Family Ginglymostomatidae. In Sharks of the World. An annotated and illustrated catalogue of shark species known to date. Volume 2. Bullhead, mackerel and carpet sharks (Heterodontiformes, Lamniformes and Orectolobiformes). FAO Species Catalogue for Fishery Purposes, no. 1, vol. 2, p. 188-201. FAO, Rome.

Carrier, J. C.

1985. Nurse sharks (Ginglymostoma cirratum) of Big Pine Key, Florida (U.S.A.): an investigation of growth and movement and a comparison of the success of several types of external tags. In Proceedings of the Fifth International Coral Reef Congress, vol. 6; Tahiti, 27 May1 June (C. Gabrie and M. Harmelin, assoc. eds.), p. 655-660. Antenne Museum-EPHE, Moorea, French Polynesia.

Carrier, J. C., H. L. Pratt, and J. I. Castro.

2004. Reproductive biology of elasmobranchs. In Biology of sharks and their relatives (J. C. Carrier, J. A. Musick, and M. R. Heithaus, eds.), p. 269-286. CRC Press, Boca Raton, FL.

Cartamil, D., N. C. Wegner, S. Aalbers, C. A Sepulveda, A. Baquero, and J. B. Graham.

2010. Diel movement patterns and habitat preferences of the common thresher shark (Alopias vulpinus) in the Southern Bight. Mar. Freshw. Res. 61:596-604. Article Castro, J. I.

2000. The biology of the nurse shark, Ginglymostoma cirratum, off the Florida east coast and the Bahama Islands. Environ. Biol. Fish. 58:1-22. Article 
Chapman, D. D., K. A. Feldheim, Y. P. Papastamatiou, and R. E. Hueter

2015. There and back again: a review of residency and return migrations in sharks, with implications for population structure and management. Annu. Rev. Mar. Sci. 7:547-570. Article

Clark, W. G., and S. M. Kaimmer.

2006. Estimates of commercial longline selectivity for Pacific Halibut (Hippoglossus stenolepis) from multiple marking experiments. Fish. Bull. 104:465-467.

Cooke, S. J., and C. D. Suski.

2005. Do we need species-specific guidelines for catch-andrelease recreational angling to effectively conserve diverse fisheries resources? Biodiversity Conserv. 14:1195-1209. Article

Cooper, A. R., and S. Morris.

1998. The blood respiratory, haematological, acid-base and ionic status of the Port Jackson shark, Heterodontus portusjacksoni, during recovery from anaesthesia and surgery: a comparison with sampling by direct caudal puncture. Comp. Biochem. Physiol., A. 119:895-903. Article

Cuthill, I.

1991. Field experiments in animal behaviour: methods and ethics. Anim. Behav. 42:1007-1014. Article

Danylchuk, A. J., C. D. Suski, J. W. Mandelman, K. J. Mur-

chie, C. R. Haak, A. M. L. Brooks, and S. J. Cooke.

2014. Hooking injury, physiological status and short-term mortality of juvenile lemon sharks (Negaprion beviros tris) following catch-and-release recreational angling. Conserv. Physiol. 2(1):cot036. Article

Davis, M. W.

2002. Key principles for understanding fish bycatch discard mortality. Can. J. Fish. Aquat. Sci. 59:1834-1843. Article

Davis, G. E., and J. W. Dodrill.

1989. Recreational fishery and population dynamics of spiny lobsters, Panulirus argus, in Florida Bay, Everglades National Park, 1977-1980. Bull. Mar. Sci. 44:78-88.

Dooley, H., and M. F. Flajnik.

2005. Shark immunity bites back: affinity maturation and memory response in the nurse shark, Ginglymostoma cirratum. Eur. J. Immunol. 35:936-945. Article

Dulvy, N. K., and R. E. Forrest.

2012. Life histories, population dynamics, and extinction risks in Chondrichthyans. In Biology of sharks and their relatives (J. C. Carrier, J. A. Musick, and M. R. Heithaus, eds.), p. 639-679. CRC Press, New York.

Evermann, B. W., and M. C. Marsh.

1900. The fishes of Porto Rico. Fish. Bull. 20:49-350

Fedorenko, A. Y.

1991. Guidelines for minimizing entrainment and impingement of aquatic organisms at marine intakes in British Columbia. Can. Manuscr. Rep. Fish. Aquat. Sci. $2098 \mathrm{E}, 86$ p. [Available from website.]

Fitzpatrick, R., M. Thums, I. Bell, M. G. Meekan, J. D. Stevens, and $\mathrm{A}$. Barnett.

2012. A comparison of the seasonal movements of tiger sharks and green turtles provides insight into their predator-prey relationship. PLoS ONE 7(12):e51927 Article

Flanagan, $\mathrm{M}$

2003. Wound measurement: can it help us to monitor progression to healing? J. Wound Care 12:189-194. Article

Frick, L. H., R. D. Reina, and T. I. Walker.

2010. Stress related physiological changes and post-re- lease survival of Port Jackson sharks (Heterodontus portusjacksoni) and gummy sharks (Mustelus antarcticus) following gill-net and longline capture in captivity. J. Exp. Mar. Biol. Ecol. 385:29-37. Article

Gallagher, A. J.

2015. Shark vulnerability to fishery interactions: assessing ecological, physiological, and social agents of risk. Ph.D. diss., 180 p. Univ. Miami, Coral Gables, FL.

Gallagher, A. J., J. E. Serafy, S. J. Cooke, and N. Hammerschlag.

2014. Physiological stress response, reflex impairment, and survival of five sympatric shark species following experimental capture and release. Mar. Ecol. Prog. Ser 496:207-218. Article

Gallagher, A. J., E. R. Staaterman, S. J. Cooke, and N. Hammerschlag.

2017. Behavioural responses to fisheries capture among sharks caught using experimental fishery gear. Can. J. Fish. Aquat. Sci. 74:1-7. Article

Gardiner, J. M.

2012. Multisensory integration in shark feeding behavior. Ph.D. diss., 267 p. Univ. S. Florida, Tampa, FL.

Gardiner, J. M., and J. Atema.

2007. Sharks need the lateral line to locate odor sources: rheotaxis and eddy chemotaxis. J. Exp. Biol. 210:1925-1934. Article

Garla, R. C., D. D. Chapman, M. S. Shivji, B. M. Wetherbee, and A. F. Amorim.

2006. Habitat of juvenile Caribbean reef sharks, Charcharhinus perezi, at two oceanic insular marine protected areas in the southwestern Atlantic Ocean: Fernando de Noronha Archipelago and Atol das Rocas, Brazil. Fish Res. 81:236-241. Article

Goodwin, J.

2009. Social determination of sex in reef fishes. Sem. Cell. Dev. Biol. 20:264-270. Article

Gurshin, C. W. D., and S. T. Szedlmayer.

2004. Short-term survival and movements of Atlantic sharpnose sharks captured by hook-and-line in the northeast Gulf of Mexico. J. Fish Biol. 65:973-986. Article

Gwinn, D. C., P. Brown, J. C. Tetzlaff, and M. S. Allen.

2011. Evaluating mark-recapture sampling designs for fish in an open riverine system. Mar. Freshw. Res. 62:835-840. Article

Heberer, C., S. A. Aalbers, D. Bernal, S. Kohin, B. DiFiore, and C. A. Sepulveda.

2010. Insights into catch-and-release survivorship and stress-induced blood biochemistry of common thresher sharks (Alopias vulpinus) captured in the southern California recreational fishery. Fish. Res. 106:495-500. Article

Heithaus, M. R., D. Burkholder, R. E. Hueter, L. I. Heithaus, H. L. Pratt Jr., and J. C. Carrier.

2007. Spatial and temporal variation in shark communities of the lower Florida Keys and evidence for historical population declines. Can. J. Fish. Aquat. Sci. 64:13021313. Article

Henningsen, A. D.

1994. Tonic immobility in 12 elasmobranchs: use as an aid in captive husbandry. Zoo Biol. 13:325-332. Article

Hoelzer, G. A.

1990. Male-male competition and female choice in the Cortez damselfish, Stegastes rectifraenum. Anim. Behav. 40:339-349. Article 
Holland, K. N., B. M. Wetherbee, C. G. Lowe, and C. G. Meyer. 1999. Movements of tiger sharks (Galeocerdo cuvier) in coastal Hawaiian waters. Mar. Biol. 134:665-673. Article

Hueter, R. E., D. A. Mann, K. P. Maruska, J. A. Sisneros, and L. S. Demski.

2004. Sensory biology of elasmobranchs. In Biology of sharks and their relatives (J. C. Carrier, J. A. Musick, and M. R. Heithaus, eds), p. 326-368. CRC Press, Boca Raton, FL.

Hyatt, M. W., P. A. Anderson, P. M. O'Donnell, and I. K. Berzins.

2012. Assessment of acid-base derangements among bonnethead (Sphyrna tiburo), bull (Carcharhinus leucas), and lemon (Negaprion brevirostris) sharks from gillnet and longline capture and handling methods. Comp. Biochem. Physiol., A 162:113-120. Article

Hyatt, M. W., P. A. Anderson, and P. M. O'Donnell.

2016. Behavioral release condition score of bull and bonnethead sharks as a coarse indicator of stress. J. Coast. Res. 32:1464-1472. Article

Jenkins, J. A., H. L. Bart Jr., P. R. Bowser, J. R. MacMillan, J. G. Nickum, J. D. Rose, P. W. Sorensen, G. W. Whitledge, J. W. Rachlin, and B. E. Warkentine.

2014. Guidelines for the use of fishes in research, $90 \mathrm{p}$. Am. Fish. Soc., Betheseda, MD.

Jones, G. P., M. J. Milicich, M. J. Emslie, and C. Lunow.

1999. Self-recruitment in a coral reef fish population. Nature 402:802-804. Article

Karl, S. A., A. L. F. Castro, and R. C. Garla.

2012. Population genetics of the nurse shark (Ginglymostoma cirratum) in the western Atlantic. Mar. Biol. 159:489-498. Article

Kessel, S. T., J. Fraser, W. G. Van Bonn, J. L. Brooks, T. L. Guttridge, N. E. Hussey, and S. H. Gruber.

2017. Transcoelomic expulsion of an ingested foreign object by a carcharhinid shark. Mar. Freshw. Res. [Online early only.] Article

Kleerekoper, H., D. Gruber, and J. Matis.

1975. Accuracy of localization of a chemical stimulus in flowing and stagnant water by the nurse shark Ginglysmostoma cirratum. J. Comp. Physiol. 98:257-275. Article

Klimley, A. P.

1980. Observations of courtship and copulation in the nurse shark, Ginglymostoma cirratum. Copeia 1980:878882.

Kohler, N. E., J. G. Casey, and P. A. Turner.

1998. NMFS Cooperative Shark Tagging Program, 196293: an atlas of shark tag and recapture data. Mar. Fish. Rev. 60(2):1-87.

Kramer, D. L., and M. R. Chapman.

1999. Implications of fish home range size and relocation for marine reserve function. Environ. Biol. Fish. 55:65-79. Article

Latour, R. J.

2005. Tagging methods and associated data analysis. In Management techniques for elasmobranch fisheries (J. A. Musick and R. Bonfil, eds.), p. 45-61. FAO Fish. Tech. Pap. 474. FAO, Rome.

Limbaugh, C.

1963. Field notes on sharks. In Sharks and survival (P. W. Gilbert, ed.), p. 63-94. Heath \& Co., Boston, MA.
McCormick, K., and J. Salcedo.

2017. SPSS statistics for data analysis and visualization, 528 p. John Wiley \& Sons, Indianapolis, IN.

Mandelman, J. W., and M. A. Farrington.

2007. The estimated short-term discard mortality of a trawled elasmobranch, the spiny dogfish (Squalus acanthias). Fish. Res. 83:238-245. Article

Mandelman, J. W., and G. B. Skomal.

2009. Differential sensitivity to capture stress assessed by blood acid-base status in five carcharihinid sharks. J. Comp. Physiol., B. 179:267-277. Article

Melhuish, J. M., P. Plassman, and K. G. Harding.

1994. Circumference, area and volume of the healing wounds. J. Wound Care 3:380-384. Article

Milsom, W. K., and E. W. Taylor.

2015. Control of breathing in elasamobranchs. In Physiology of elasmobranch fishes: internal processes, vol. 34B (R. E. Shadwick, A. P. Farrell, and C. J. Brauner, eds.), p. 83-126. Academic Press, Oxford, UK.

Morgan, A., and J. K. Carlson.

2010. Capture time, size and hooking mortality of bottom longline-caught sharks. Fish. Res. 101:32-37. Article

Motta, P. J.

2004. Prey capture behavior and feeding mechanics of elasmobranchs. In Biology of sharks and their relatives (J. C. Carrier, J.A. Musick, and M.R. Heithaus, eds.), p. 165-202. CRC Press, Boca Raton, FL.

Motta, P. J., R. E. Hueter, T. C. Tricas, and A. P. Summers. 2002. Kinematic analysis of suction feeding in the nurse shark, Ginglymostoma cirratum (Orectolobiformes, Ginglymostomidae). Copeia 2002:24-38. Article

Motta, P. J., R. E. Hueter, T. C. Tricas, A. P. Summers, D. R. Huber, D. Lowry, K. R. Mara, M. P. Matott, L. B. Whitenack, and A. P. Wintzer.

2008. Functional morphology of the feeding apparatus, feeding constraints, and suction performance in the nurse shark Ginglymostoma cirratum. J. Morphol. 269:1041-1055. Article

Naresh, M. D., V. Arumgam, and R. Sanjeevi.

1997. Mechanical behaviour of shark skin. J. Biosci. 22:431-437. Article

Nelson, D. R., R. R. Johnson, J. N. McKibben, and G. G. Pittenger.

1986. Agonistic attacks on divers and submersibles by gray reef sharks, Carcharinus amblyrhynchos: antipredatory or competitive? Bull. Mar. Sci. 38:68-88. [Available from website]

Olsen, A. M.

1953. Tagging of school shark, Galeorhinus australis (Macleay) (Carcharanidae) in south-eastern Australian waters. Aust. J. Mar. Freshw. Res. 4:95-107. Article

Osgood, G. J., and J. K. Baum.

2015. Reef sharks: recent advances in ecological understanding to inform conservation. J. Fish Biol. 87:1489-1523. Article

Pine, W. E., K. H. Pollock, J. E. Hightower, T. J. Kwak, and J. A. Rice.

2003. A review of tagging methods for estimating fish population size and components of mortality. Fisheries 28:10-23. https://doi.org/10.1577/1548-8446(2003)28 [10:AROTMF]2.0.CO;2

Pratt, H. L., Jr., and J.C. Carrier.

2001. A review of elasmobranch reproductive behavior with a case study on the nurse shark, Ginglymostoma cirratum. Environ. Biol. Fish. 60:157-188. Article 
Reif, W.-E.

1978. Wound healing in sharks: form and arrangement of repair scales. Zoomorphologie 90:101-111. Article

Ricci, J. A., C. R. Vargas, D. Singhal, and B. T. Lee.

2016. Shark attack-related injuries: epidemiology and implications for plastic surgeons. J. Plast. Reconstr. Aesthet. Surg. 69:108-114. Article

Rosa, R. S., A. L. F. Castro, M. Furtado, J. Monzini, and R. D. Grubbs.

2006. Ginglymostoma cirratum. The IUCN List of Threatened Species 2006: e.T60223A12325895. [Available from website]

Rosenzweig, L. J.

1988. Anatomy of the shark: text and dissection guide, 120 p. W.C. Brown Publs., Dubuque, IA.

Schemnitz, S. D., G. R. Batcheller, M. J. Lovallo, H. B. White, and M. W. Fall.

2012. Capturing and handling wild animals. In The wildlife techniques manual, vol. 1 (N. J. Silvy, ed.), p. 64-117. Johns Hopkins Univ. Press, Baltimore, MD.

Sedgewick, J.

2008. Scientific imaging with Photoshop: methods, measurement, and output, 312 p. New Riders Press, Berkeley, CA.

Sepulveda, C. A., C. Heberer, S. A. Aalbers, N. Spear, M. Kinney, D. Bernal, and S. Kohin.

2015. Post-release survivorship studies on common thresher sharks (Alopias vulpinus) captured in the southern California recreational fishery. Fish. Res. 161:102-108. Article

Shadwick, R. E., and J. A. Goldbogen.

2012. Muscle function and swimming in sharks. J. Fish Biol. 80:1904-1939. Article

Shapiro, D. Y. and R. H. Boulon Jr.

1982. The influence of females on the initiation of femaleto-male sex change in a coral reef fish. Horm. Behav. 16:66-75. Article

Sheriff, M. J., B. Dantzer, B. Delehanty, R. Palme, and R. Boonstra.

2011. Measuring stress in wildlife: techniques for quantifying glucocorticoids. Oecolgia 166:869-887. Article

Silvy, N. J.

2012. The wildlife techniques manual, vol. $1-2,7^{\text {th }}$ ed., 1136 p. John Hopkins Univ. Press, Baltimore, MD

Skomal, G. B.

2007. Evaluating the physiological and physical consequences of capture on post-release survivorship in large pelagic fishes. Fish. Manag. Ecol. 14:81-89. Article
Skomal, G. B., and D. Bernal.

2010. Physiological responses to stress in sharks. In Sharks and their relatives II: biodiversity, adaptive physiology, and conservation (J. C. Carrier, J. A. Musick, and M. R. Heithaus, eds.), p. 460-484. CRC Press, Boca Raton, FL.

Smith, M. F. L.

1992. Capture and transportation of elasmobranchs, with emphasis on the grey nurse shark (Carcharias taurus). Aust. J. Mar. Freshw. Res. 43:325-343. Article

Stevens, J. D., R. Bonfil, N. K Dulvy, and P. A. Walker.

2000. The effects of fishing on sharks, rays, and chimaeras (chondrichthyans), and the implications for marine ecosystems. ICES J. Mar. Sci. 57:476-494. Article

Tanaka, S. K.

1973. Suction feeding by the nurse shark. Copeia 1973: 606-608.

Towner, A., M. J. Smale, and O. Jewel.

2012. Boat-strike wound healing in Carcharodon carcharias. In Global perspectives on the biology and life history of the white shark (M. L. Domeier, ed.), p. 7783. CRC Press, Boca Raton, FL.

Wainwright, S. A., F. Vosburgh, and J. H. Hebrank.

1978. Shark skin: function in locomotion. Science 202:747-749. Article

Webster, M. S., and M. A. Hixon.

2000. Mechanisms and individual consequences of intraspecific competition in a coral-reef fish. Mar. Ecol. Prog. Ser. 196:187-194. Article

Whitney, N. M., K. O. Lear, L. C. Gaskins, and A. C. Gleiss. 2016. The effects of temperature and swimming speed on the metabolic rate of the nurse shark (Ginglymostoma cirratum, Bonaterre). J. Exp. Mar. Biol. Ecol. 477:40-46. Article

Wiley, T. R., and C. A. Simpfendorfer.

2007. The ecology of elasmobranchs occurring in the Everglades National Park, Florida: Implications for conservation and management. Bull. Mar. Sci. 80:171-189.

Wilga, C. D., and G. V. Lauder.

2002. Function of the heterocercal tail in sharks: quantitative wake dynamics during steady horizontal swimming and vertical maneuvering. J. Exp. Biol. 205:2365-2374.

Williams, B. K., J. D. Nichols, and M. J. Conroy.

2002. Analysis and management of animal populations, 817 p. Academic Press, San Diego, CA.

Zeller, D. C. and G. R. Russ.

1998. Marine reserves: patterns of adult movement of the coral trout (Plectropomus leopardus (Serranidae)). Can. J. Fish Aquat. Sci. 55:917-924. Article 